\title{
Prevalence of Obesity in School Children and Its Relation to Lifestyle Behaviors in Al-Ahsa District of Saudi Arabia
}

\author{
Ahmed A. Albin Saleh ${ }^{1}$, Aqeel S. Alhaiz ${ }^{1}$, Ataur Rahman Khan ${ }^{1}$, Abdulkareem J Al-Quwaidhi ${ }^{2}$, Majdi Aljasim ${ }^{1}$, \\ Adeeb Almubarak ${ }^{1}$, Ahmed Alqurayn ${ }^{1}$, Mohammed Alsumaeil ${ }^{1}$ \& Akeel Al Yateem ${ }^{3}$ \\ ${ }^{1}$ Specialist of Family Medicine, Family Medicine Center, Eastern province, KSA \\ ${ }^{2}$ Consultant Epidemiologist and Public Health Physician, Eastern province, KSA \\ ${ }^{3}$ Resident in field of Epidemiology, Eastern province, KSA \\ Correspondence: Dr Ataur Rahman Khan, Community Ophthalmologist and Public Health Specialist, PO Box \\ 9136, Omran Primary Health Center, Al omran, Al ahsa 31982, Kingdom of Saudi Arabia.
}

Received: September 29, 2017 Accepted: October 13, 2017 Online Published: October 22, 2017

doi:10.5539/gjhs.v9n12p80 URL: https://doi.org/10.5539/gjhs.v9n12p80

\begin{abstract}
Objectives: To estimate obesity prevalence among children and adolescents in Al-Ahsa, Saudi Arabia for the year 2016 and to determine the related preventable risk factors.

Methods: This study was a cross-sectional study (using stratified random sampling representing different geographical areas of Al-Ahsa) through a self-administered questionnaire. It included 240 male students aged (715) years old from public primary and intermediate schools in Al-Ahsa governorate, Kingdom of Saudi Arabia. Anthropometric measurements of weight and height were taken for all the study participants. Body mass index (BMI) and its percentile was determined using Saudi won growth charts of the corresponding age and sex.

Results: The overall prevalence of overweight and obesity was $29.6 \%$ (10.8\% overweight, $3.8 \%$ obese, and $15 \%$ extremely obese). The prevalence of overweight and obesity was significantly associated with early childhood obesity, parental obesity, mother's employment, family income, number of snacks and fast food consumption, physical inactivity, and time spent in watching television. Other factors (namely, eating during emotional stress, family gathering on meals, and regular eating times) were having independently significant association.
\end{abstract}

Conclusion: There is an urgent need to spread awareness about obesity, and the prevention programs that involving schools and families are the key strategy for controlling the current epidemic of obesity.

Keywords: obesity, life style, behavior

\section{Introduction}

Obesity is defined by the World Health Organization (WHO) as "a condition of excessive body fat or adiposity which exceeds healthy limits that presents a risk to the health" (WHO; 2011). On the other hand, it is defined by the American National Institutes of Health (NIH) as the "condition of having an abnormally high proportion of fat, a complex multifactorial chronic disease that develops from an interaction of genotype and the environment" (Gumbiner, 2001).

Obesity is becoming one of the most important concerns that affect the wellbeing of populations. It is a major public health problem resulting in serious social, physical and psychological damage (The NHS Information Centre, 2008). Some recent data published in Canadian Journal of Diabetes reported that around 67\% of type 2 diabetes cases, $24 \%$ of osteoarthritis cases, $17 \%$ of colorectal cancers, $11 \%$ of depression cases, and $20 \%$ of premature deaths in adults are estimated to be directly attributable to obesity in Canada (Janssen, 2013).

By the end of the $20^{\text {th }}$ century, the WHO has considered obesity as a 'global epidemic' that has involved all age groups (WHO, consultation on Obesity, 1997). It is responsible for more than two million deaths each year regardless of economic status of the countries (WHO, ten facts on obesity, 2010). However, Obesity is not an issue limited to adults anymore, as it is increasingly manifested among children (Reilly, 2005). Obese children are more likely to become obese adults, which make them more liable to diabetes and cardiovascular diseases at an earlier age. A systematic review showed that the risk of overweight children becoming overweight adults was at least twice as high as for normal weight children (Eating, Activity, \& Durham, 2013). This was supported by a cohort 
study carried out among Danish school children aged 7 to 13 years, for whom measurements of height and weight were available. The study concluded that higher BMI during childhood was associated with an increased risk of coronary heart disease (CHD) in adulthood (Baker, Olsen, \& Sørensen, 2007). Furthermore, A study conducted in Australia showed that the overweight and obese children were more likely to complain of musculoskeletal pain, depression, anxiety and bullying, and they had more abnormal laboratory tests, such as impaired glucose tolerance, dyslipidemia, raised alanine transaminase, and hyperinsulinism (Bell et al., 2011).

Globally, there are a total of 155 million (1 in 10) children overweight, and around 30-45 million classified as obese (Wang \& Lobstein, 2006). The incidence of obesity-related conditions is increasing steeply among adolescents, which reflects the growing burden of such a problem (WHO \& IDF, 2004). Obesity epidemic is not only prevalent in the high- income countries, but also in low- and middle-income countries (WHO, Ten facts on obesity, 2010).According to the relatively recent surveys in the United States of America, the prevalence of childhood obesity has increased across all racial/ethnic groups, socioeconomic groups, ages, and in both sexes (Kliegman, Behrman, Jenson, \& Stanton, 2007). In Canada, the prevalence of childhood obesity has tripled since 1980s (Janssen, 2013).

In Europe, the last WHO surveillance initiative conducted in 2008 across 12 European countries has revealed that $19.3 \%-49.0 \%$ of boys and $18.4 \%-42.5 \%$ of girls (aged 6-9 years) were overweight. However the prevalence of obesity ranged from $6.0 \%$ to $26.6 \%$ among boys and from $4.6 \%$ to $17.3 \%$ among girls $(n=168832)$. These multi-country comparisons suggested the presence of a north-south gradient with the highest level of overweight found in southern European countries (Wijnhoven et al., 2013). However, childhood obesity remains under-recognized and undertreated (Ogden, Carroll, Kit, \& Flegal, 2012).

Of children who seek medical advice, less than half of them receive body mass index (BMI) screening and/or preventive counseling about diet and physical activity as recommended by the American Academy of Pediatrics (Rausch, Perito, \& Hametz, 2007; Barlow, 2007; Anna, Áine, Joann, \& Sanjay, 2013).

A recent review has demonstrated that the Middle East region has the highest dietary energy surplus among developing countries, and there was evidence of a rapid rise in non-communicable disease risk factors, especially obesity (Mirmiran P, Sherafat-Kazemzadeh R, Jalali-Farahani S and Azizi F, 2010).The highest rates of childhood obesity and overweight were reported from Bahrain and the lowest from Iran. Studies from Saudi Arabia, Iran and Kuwait showed an upwards trend in childhood obesity compared with a decade ago (Mirmiran, Sherafat-Kazemzadeh, Jalali-Farahani, \& Azizi, 2010). The other Gulf countries are not exempted. Surveys showed high prevalence of overweight and obesity among children in almost all Gulf countries (Al-Dossary et al., 2010).

In Saudi Arabia, several studies were conducted in different areas and Provinces, and reported a high prevalence of overweight and obesity (Al-Dossary et al., 2010). However, this problem is still increasing in spite of the national prevention programs which have been implemented. One study conducted in Riyadh in 2003 showed that the prevalence of overweight among adolescents was $13.8 \%$ and obesity was $20.5 \%$. Among the risk factors, family history (odds ratio, 2.49; 95\% confidence interval, 1.72-3.61) and lack of physical activity (odds ratio, 1.63; 95\% confidence interval, 1.01-2.62) were associated with adolescent obesity. Twenty percent of overweight participants did not think that they were overweight (Al-Rukban, 2003). Another study was carried out in Riyadh to compare the prevalence of obesity among schoolboys between 1988 and 2005, and found that the prevalence was increasing substantially (from $3.4 \%$ in 1988 to $24.5 \%$ in 2005) (Al-Hazzaa, 2007).

In Abha, a study was conducted in 2008 among schoolboys aged $11-19$ years revealed that $16 \%$ of them were obese, and the main associated factor was lack of exercise (Mahfouz et al., 2007). While in Al- Ahsa region (Eastern province of Saudi Arabia), a number of surveys were conducted regarding the obesity in schoolchildren. For example, a cross-sectional study included 1,139 Saudi males aged 10 to 14 years, concluded that the prevalence of overweight was $14.2 \%$, while obesity was $9.7 \%$. The prevalence was higher in urban areas, older age groups, students with lower educated and more working mothers. Missing and / or infrequent intake of breakfast at home, frequent consumption of fast foods, low servings of fruits, vegetables, milk and dairy product per day, with frequent consumption of sweets/candy and carbonated drinks were all predictors of obesity and overweight among the included males (Amin, Al-Sultan, \& Ali, 2008). Another study has been recently conducted in Al Ahsa, included 1270 volunteered adolescents living in different urban and rural areas. The study showed that the prevalence of overweight was $16.8 \%$ and $18.8 \%$ for males and females, respectively and for obesity was $19.1 \%$ and $17.7 \%$ for males and females, respectively. This equates to a total of $35.9 \%$ of males and $36.5 \%$ of females being overweight or obese (Ami, Al-Sultan, \& Ali, 2012). 


\section{Material and Methods}

This was a cross-sectional study (using stratified random sampling representing different geographical areas) through the questionnaires. The study was conducted on a sample of children who attended public schools during the second term $\left(26^{\text {th }}\right.$ of January to $25^{\text {th }}$ of May 2016). All the male students aged 7-15 years from governmental schools of Al Hasa (primary and intermediate schools) were the study population. A list of all public primary and intermediate schools for males in Al-Ahsa was obtained from Al-Ahsa General Directorate of Education with detail information of the children. A multistage stratified random sampling method was adopted to select the sample for the present study In order to select children from families of different socioeconomic levels. Al-Ahsa area was divided into two strata (cities and villages). Ten schools (five primary schools, and five intermediate schools) were selected from each stratum using simple random technique. From each school selected, one class (from each educational level) was randomly chosen to be included in the study. 5 students from each primary school level and 10 students from each secondary school level were selected by using systemic random sampling technique. So, the total number of estimated sample size was 300 . For every student, and school a unique code was generated, which was printed on the questionnaires. For confidentiality reasons, the names of the students and the schools were not printed on the questionnaires.

The exclusion criteria was the children aged $<7$ or $>15$ years, children whose exact birth date were not available, children without written informed consent, and children who left more than $20 \%$ of the questionnaire not answered were be excluded from the data analysis.

Socio-demographic data included age, sex, nationality and place of residence. Personal factors included food choices, self-esteem, physical activity, and sedentary life habits. Family related factors included the age and nationality of parents, level of education, job and obesity among parents, family eating pattern, and awareness of obesity in their children. Environmental/institutional factors contained the environment and health education program.

Four-pages of questionnaire were designed in English, and then translated to Arabic with the consultation of experts of Dammam University, Saudi Arabia. It composed of 3 parts: socio-demographic data, personal factors, and factors related to the family and environment. Most questions were of one of two types: the yes/no questions, which offer a dichotomous choice; and the multiple choice questions, which offer several fixed alternatives. And at the end, the parents were asked optionally to write an E-mail to supply them with the final results and recommendations of the study. A pilot study on 30 children was done before undertaking the main study. These students were excluded from the study.

Data was collected by the principal investigator himself, with the help of teachers from each school. Before data collection, official letters were sent to the headmaster of the selected schools explaining the purpose and the aims of the study to facilitate the process. Then the researcher visited each school, two or three teachers were trained to collect information and fill in the questionnaire. .Primarily the researcher interviewed students to explain how the questionnaire would be filled by their parents. Then, the researcher interviewed each student to fill the first page of the questionnaire. After that, the weight and height were measured by the researcher. Children were weighed while wearing minimal clothing and without shoes. The researcher used a suitable electronic balance (Detecto type, USA). The scale was checked and standardized daily before use. Then, the height of each student was measured using suitable tape meter scale that fixed to the wall. The researcher measured the heights of the subjects without shoes, taking into account that heels, buttocks, shoulders and head are close to vertical wall surface. Finally, students were asked to take the questionnaire to home to be filled by one of their parents or older family member, and to be collected again on the next day.

Data from the completed questionnaires were entered into Statistical Package for the Social Sciences (SPSS) software on the researcher's personal computer. The data were coded and analyzed using the SPSS version 21. Continuous variables were expressed as mean, median, and standard deviation, while categorical variables were expressed as frequency. T-test was used to test significance between continuous variables, while a $\mathrm{Chi}^{2}$ test was used to test independency between categorical data. Logistic regression analysis was carried out using binary variables: normal weight versus abnormal weight (obese or overweight) as a dependent variable and a number of other variables as independent variables. A P-value of $\leq \mathbf{0 . 0 5}$ was the criterion of statistical significance. Microsoft Excel program version 11.0 was used for correlation graphs plotting. All data analysis processing was checked by a biostatistician from Dammam University throughout the study.

Using a previously designed program on Medscape website, the investigator calculated BMI and its percentiles depending on sex, age (in years), height (in centimeters), and weight (in kilograms) of each child. Children were categorized into five groups (76): Underweight $\left(<5^{\text {th }}\right.$ percentile), Healthy weight $\left(>5^{\text {th }}\right.$ percentile and $<85^{\text {th }}$ 
percentile), Overweight $\left(>85^{\text {th }}\right.$ percentile and $<95^{\text {th }}$ percentile $)$, Obese $\left(>95^{\text {th }}\right.$ percentile $)$. Extremely obese $\left(>97^{\text {th }}\right.$ percentile)

Ethical clearance and approval to conduct the field survey was obtained from the Research Center Ethical Committee, Ministry of Education and School Health Unit in the corresponding areas. Before start the interview consent form was taken from parents and children.

\section{Results}

This study included 240 participants; all of them were male students. The mean age and standard deviation of the participants was $11.75( \pm 2.557)$ years (Range $7-15$ years). The analysis of socio-demographic variables summarized in Table 1. Almost twenty four percent of the students were 9 years and less, $22.5 \%$ were 10-12 years old, and $53.7 \%$ were 13 years and above. More than ninety nine percent of the students were Saudis. Fathers of $19 \%$ of the students had higher education while $25.8 \%, 24.2 \%$ and $31 \%$ had secondary, intermediate and primary or less level of education respectively. In comparison, $71.1 \%$ of mothers had higher education, $28.3 \%$ secondary, $24.2 \%$ intermediate, and $30.4 \%$ had primary or less level of education. Fathers of $77.1 \%$ of the students were working, while $22.9 \%$ were either retired or unemployed. The majority of mothers $(87.9 \%)$ were housewives and only $12.1 \%$ were working. The mean and standard deviation of the anthropometric measurements for the included children were as: Weight: $41.7 \pm 16.4 \mathrm{~kg}$; Height: $143 \pm 15 \mathrm{~cm}$; and for BMI: $19.8 \pm 5.2 \mathrm{~kg} / \mathrm{m}^{2}$.

Table 1. Characteristics of the study population

\begin{tabular}{|c|c|c|c|}
\hline Variables & & Number & Percent \\
\hline \multirow[t]{4}{*}{ Age (Years) } & Mean \pm SD & $11.75( \pm 2.557)$ & \\
\hline & $\leq 9$ & 57 & $23.8 \%$ \\
\hline & $10-12$ & 54 & $22.5 \%$ \\
\hline & $\geq 13$ & 129 & $53.7 \%$ \\
\hline \multirow[t]{4}{*}{ Father's Education } & Primary or less & 74 & $30.9 \%$ \\
\hline & Intermediate & 58 & $24.2 \%$ \\
\hline & Secondary & 62 & $25.8 \%$ \\
\hline & Higher Education & 46 & $19.2 \%$ \\
\hline \multirow[t]{4}{*}{ Mother's Education } & Primary or less & 73 & $30.4 \%$ \\
\hline & Intermediate & 58 & $24.2 \%$ \\
\hline & Secondary & 68 & $28.3 \%$ \\
\hline & Higher Education & 41 & $17.1 \%$ \\
\hline \multirow[t]{2}{*}{ Father's Work } & Working & 185 & $77.1 \%$ \\
\hline & Not working & 55 & $22.9 \%$ \\
\hline \multirow[t]{2}{*}{ Mother's Work } & Employed & 29 & $12.1 \%$ \\
\hline & Housewives & 211 & $87.9 \%$ \\
\hline \multirow{3}{*}{$\begin{array}{l}\text { Anthropometric } \\
\text { Measurements Mean } \pm \text { SD }\end{array}$} & Weight (kg) & $41.7 \pm 16.4$ & \\
\hline & Height $(\mathrm{cm})$ & $143 \pm 15$ & \\
\hline & BMI (kg/m2) & $19.8 \pm 5.2$ & \\
\hline
\end{tabular}

Among the 240 participants, $29.6 \%$ were either overweight or obese (10.8\% of the children were overweight, $3.8 \%$ were obese, and $15 \%$ of them were extremely obese). On the other hand, $10 \%$ of the total participants were underweight. The details are shown in Table 2. 
Table 2. The nutritional status of public primary intermediate school children

\begin{tabular}{lll}
\hline Nutritional Status & Number & Percent \\
\hline Underweight & 24 & $10 \%$ \\
Normal weight & 145 & $60.4 \%$ \\
Overweight & 26 & $10.8 \%$ \\
Obese & 9 & $3.8 \%$ \\
Extremely obese & 36 & $15 \%$ \\
\hline
\end{tabular}

The prevalence of increased weight (overweight or obesity) among the studied children showed progressive increase with age. The association between body weight and age was statistically insignificant (P-value $=0.07$ ). Presence of obesity in the early childhood was positively associated with overweight/obesity in the current age of children, and it showed a statistically significant association (P-value $<0.05$ ). There was no statistically significant association between overweight/obesity and the living area. However, distribution was almost similar between urban (cities) and rural (villages) areas (Table 3).

Table 3. Prevalence of overweight/obesity according to age

\begin{tabular}{llll}
\hline & \multicolumn{2}{l}{ BMI Categories No, (\%) } & \\
\cline { 2 - 4 } Ane & Underweight & Increased weight \\
$\leq 9$ years & $3(12.5 \%)$ & $42(29 \%)$ & $12(16.9 \%)$ \\
$10-12$ years & $5(20.8 \%)$ & $27(18.6 \%)$ & $22(31 \%)$ \\
$\geq 12$ years & $16(66.7 \%)$ & $76(52.4 \%)$ & $37(52.1 \%)$ \\
\hline P-value $=0.07$ & & $2(1.4 \%)$ & $7(9.9 \%)$ \\
\hline Early childhood obesity & & $143(98.6 \%)$ & $64(90.1 \%)$ \\
Was obese & $0(0.0 \%)$ & & \\
Wasn't obese & $24(100 \%)$ & & $40(56.3 \%)$ \\
\hline P-value $=0.005$ & & $71(49 \%)$ & $31(43.7 \%)$ \\
\hline Living area & $12(50 \%)$ & $74(51 \%)$ & \\
Urban & $12(50 \%)$ & & \\
Rural & & & \\
\hline P-value $=0.6$ & & & \\
\hline
\end{tabular}

As far as parents education is concerned both fathers and mother's educational level had statistically insignificant association with the child's BMI (Table 4). 
Table 4. Prevalence of overweight/obesity according to parents' education

\begin{tabular}{llll}
\hline \multirow{2}{*}{ Education } & BMI Categories & \\
\cline { 2 - 3 } Father's education & Underweight & Normal weight & Increased weight \\
Primary or less & $11(45.8 \%)$ & $46(31.7 \%)$ & $17(23.9 \%)$ \\
Intermediate & $7(29.2 \%)$ & $30(20.7 \%)$ & $21(29.6 \%)$ \\
Secondary & $5(20.8 \%)$ & $41(28.3 \%)$ & $16(22.5 \%)$ \\
Higher education & $1(4.2 \%)$ & $28(19.4 \%)$ & $17(23.9 \%)$ \\
\hline P-value $=0.18$ & & & $21(29.6 \%)$ \\
\hline Mother's education & $8(33.3 \%)$ & $44(30.4 \%)$ & $14(19.7 \%)$ \\
Primary or less & $10(41.7 \%)$ & $34(23.4 \%)$ & $19(26.8 \%)$ \\
intermediate & $4(16.7 \%)$ & $45(31 \%)$ & $17(23.9 \%)$ \\
Secondary & $2(8.3 \%)$ & $22(15.2 \%)$ & \\
Higher education & & & \\
\hline P-value 0.3 & & & \\
\hline
\end{tabular}

P-value $=0.3$

Mother's employment was statistically significant and showed a strong association with the child's BMI (P-value < 0.0001). However, father's employment was not significantly associated (Table 5).

Table 5. Prevalence of overweight/obesity according to parents' Employment

\begin{tabular}{llll}
\hline \multirow{2}{*}{ Employment } & BMI Categories & & \\
\cline { 2 - 4 } & Underweight & Normal weight & Increased weight \\
\hline Fathers employment & $6(25 \%)$ & $33(22.8 \%)$ & $16(22.5 \%)$ \\
Unemployed & $18(75 \%)$ & $112(77.2 \%)$ & $55(77.5 \%)$ \\
Employed & & & \\
\hline P-value $>0.05$ & $23(95.8 \%)$ & $136(93.8 \%)$ & $52(73.2 \%)$ \\
\hline Mother's employment & $1(4.2 \%)$ & $9(6.2 \%)$ & $19(12.1 \%)$ \\
Housewife & & & \\
Employed & & & \\
\hline P-value $<0.0001$ & & & \\
\hline
\end{tabular}

It was found that the parental obesity had a significant association with the child obesity, meaning that the increase in father's and/or mother's weight was substantially leaded to increase in the child's BMI. Overweight / obesity among children was higher when both parents were obese, however, it was not statistically significant (Table 6). 
Table 6. Prevalence of overweight/obesity according to the parental obesity

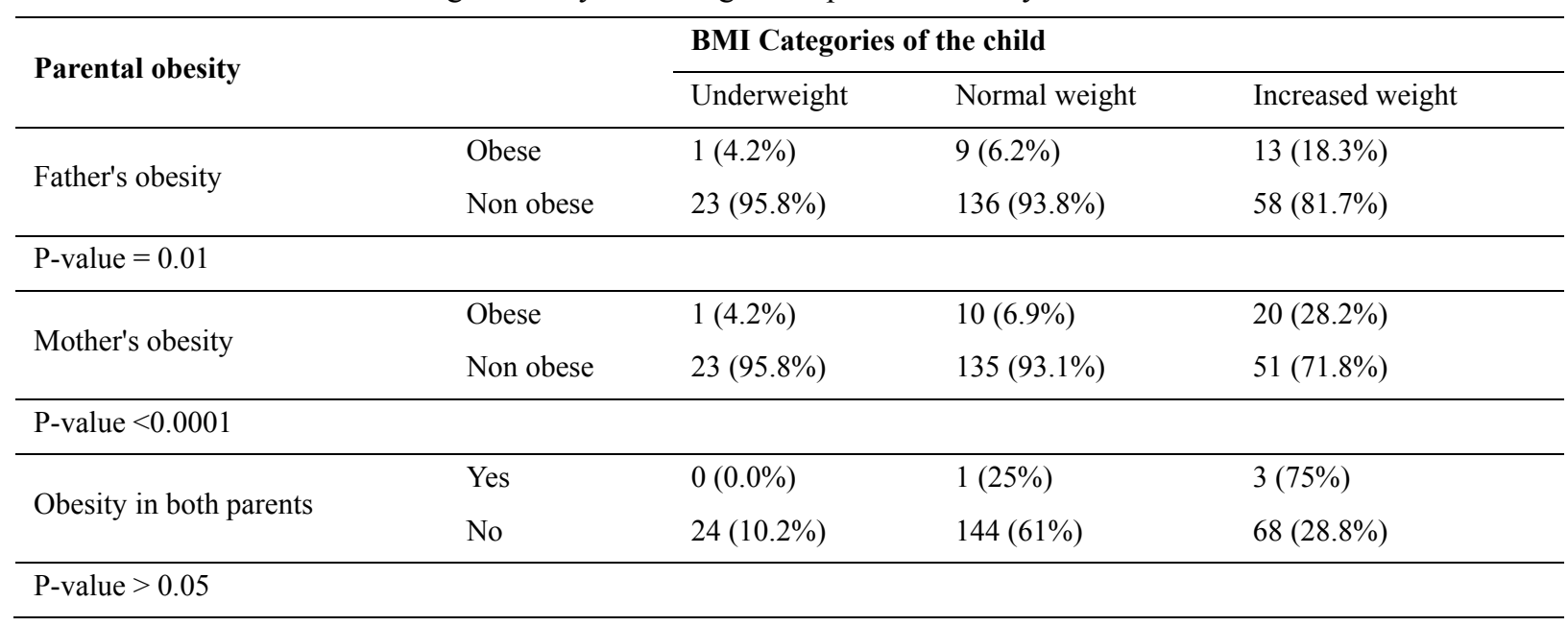

Data showed that the monthly income of the family had a statistically significant association with the prevalence of obesity in children in this study, i.e. the prevalence of obesity was increased with the increase in family income (Table 7).

Table 7. Prevalence of overweight/obesity according to monthly family income

\begin{tabular}{llll}
\hline \multirow{2}{*}{ Monthly income } & \multicolumn{2}{l}{ BMI Categories (No., \%) } & \\
\cline { 2 - 4 } & Underweight & Normal weight & Increased weight \\
\hline$<3000$ S.R. & $15(20.4 \%)$ & $41(55.4 \%)$ & $18(24.3 \%)$ \\
$3000-6000$ S.R. & $6(8.7 \%)$ & $43(62.3 \%)$ & $20(29 \%)$ \\
$6000-9000$ S.R. & $2(4 \%)$ & $30(60 \%)$ & $18(36 \%)$ \\
$9000-12000$ S.R. & $1(4.2 \%)$ & $17(70.8 \%)$ & $6(25 \%)$ \\
$>12000$ S.R. & $0(0 \%)$ & $14(60.9 \%)$ & $9(39.1 \%)$ \\
\hline P-value $=0.04$ & & & \\
\hline
\end{tabular}

The prevalence of overweight/obesity was positively increased with higher number of meals, snakes /day, eating fast food and carbonated drinks consumption. However, there was no statistically significant association with higher number of meal and carbonated drinks consumption. Higher rates of fast food consumption ( $\geq 5$ times/week) were observed among overweight/obese children when compared with non-obese ones. However, the percentage of overweight/obese children was constantly increasing with the number of cans consumed daily (Table 8). 
Table 8. Prevalence of overweight/obesity according to Number of main meals/day, snacks, fast food and carbonated drinks

\begin{tabular}{|c|c|c|c|}
\hline & \multicolumn{3}{|c|}{ BMI Categories } \\
\hline & Underweight & Normal weight & Increased weight \\
\hline \multicolumn{4}{|c|}{ Number of meals/day } \\
\hline$\leq 2$ & $8(11.9 \%)$ & $44(65.7 \%)$ & $15(22.4 \%)$ \\
\hline $3-4$ & $15(9 \%)$ & $97(58.4 \%)$ & $54(32.5 \%)$ \\
\hline$\geq 5$ & $1(12.5 \%)$ & $4(54.1 \%)$ & $2(33.3 \%)$ \\
\hline \multicolumn{4}{|l|}{ P-value $=0.3$} \\
\hline \multicolumn{4}{|c|}{ Number of snacks/day } \\
\hline$\leq 2$ & $15(12.4 \%)$ & $58(47.9 \%)$ & $48(39.7 \%)$ \\
\hline $3-4$ & $9(8.7 \%)$ & $80(76.9 \%)$ & $15(14.4 \%)$ \\
\hline$>4$ & $0(0.0 \%)$ & $7(46.7 \%)$ & $8(53.3 \%)$ \\
\hline \multicolumn{4}{|c|}{ P-value $<0.0001$} \\
\hline \multicolumn{4}{|c|}{ No. of fast food/week } \\
\hline Not eating & $6(9.4 \%)$ & $51(79.7 \%)$ & $7(10.9 \%)$ \\
\hline$\leq 2$ & $15(12.8 \%)$ & $68(58.1 \%)$ & $34(29.1 \%)$ \\
\hline $3-4$ & $2(5.6 \%)$ & $17(47.2 \%)$ & $17(47.2 \%)$ \\
\hline$\geq 5$ & $1(7.1 \%)$ & $9(36.2 \%)$ & $13(56.7 \%)$ \\
\hline \multicolumn{4}{|c|}{ P-value $=0.001$} \\
\hline \multicolumn{4}{|c|}{ No. of carbonated drinks/day } \\
\hline Not drinking & $6(18.8 \%)$ & $23(71.9 \%)$ & $3(9.4 \%)$ \\
\hline$\leq 2$ & $17(9.3 \%)$ & $108(59.3 \%)$ & $57(31.3 \%)$ \\
\hline $3-4$ & $0(0.0 \%)$ & $12(60 \%)$ & $8(40 \%)$ \\
\hline$\geq 5$ & $1(16.7 \%)$ & $2(33.3 \%)$ & $3(50 \%)$ \\
\hline
\end{tabular}

The prevalence of overweight / obesity was higher among those who eat the meal while watching TV. Eating during emotional stress such as anger or sadness was also assessed, but no statistically significant association was found with the prevalence of overweight/obesity. The prevalence of overweight/obesity among children who did not practice physical activities during leisure times was obviously higher than those who practiced it, and the association was statistically significant. Different types of outdoor sports were assessed, such as running, football, basketball, swimming, and aerobic exercises. The prevalence of overweight/obesity was shown to be significantly associated with the duration of playing of football (P-value $<0.0001$ ), i.e. the prevalence was high among children in whom the frequency of playing was less than four times per week. However the other sports were not significantly associated with the overweight/obesity among the included subjects (Table 9) (Figure 2). 
Table 9. Prevalence of overweight/obesity and its association with eating while watching TV and during emotional stress

\begin{tabular}{|c|c|c|c|c|}
\hline \multirow{2}{*}{ Eating habit } & & \multicolumn{3}{|l|}{ BMI Categories } \\
\hline & & Underweight & Normal weight & Increased weight \\
\hline \multirow{2}{*}{ Eating while watching TV } & Yes & $22(10.8 \%)$ & $124(60.8 \%)$ & $58(28.4 \%)$ \\
\hline & No & $2(5.6 \%)$ & $21(58.3 \%)$ & $13(36.1 \%)$ \\
\hline \multicolumn{5}{|l|}{$\mathrm{P}$-value $=0.4$} \\
\hline \multirow{2}{*}{ Eating during emotional stress } & Yes & $1(4.3 \%)$ & $12(52.2 \%)$ & $10(43.5 \%)$ \\
\hline & No & $23(10.6 \%)$ & $133(61.3 \%)$ & $61(28.1 \%)$ \\
\hline \multicolumn{5}{|l|}{ P-value $=0.2$} \\
\hline \multirow{2}{*}{ Physical activity in leisure time } & Yes & $17(12.2 \%)$ & $89(64 \%)$ & $33(23.7 \%)$ \\
\hline & No & $7(6.9 \%)$ & $56(55.4 \%)$ & $38(37.6 \%)$ \\
\hline \multicolumn{5}{|l|}{$\mathrm{P}$-value $=0.046$} \\
\hline \multicolumn{5}{|l|}{ Playing football/week } \\
\hline Not playing & & $3(6.7 \%)$ & $15(33.3 \%)$ & $27(60 \%)$ \\
\hline$\leq 4$ times/week & & $18(11.7 \%)$ & $98(63.6 \%)$ & $38(24.7 \%)$ \\
\hline$>4$ times/week & & $3(7.3 \%)$ & $32(78 \%)$ & $6(14.6 \%)$ \\
\hline
\end{tabular}

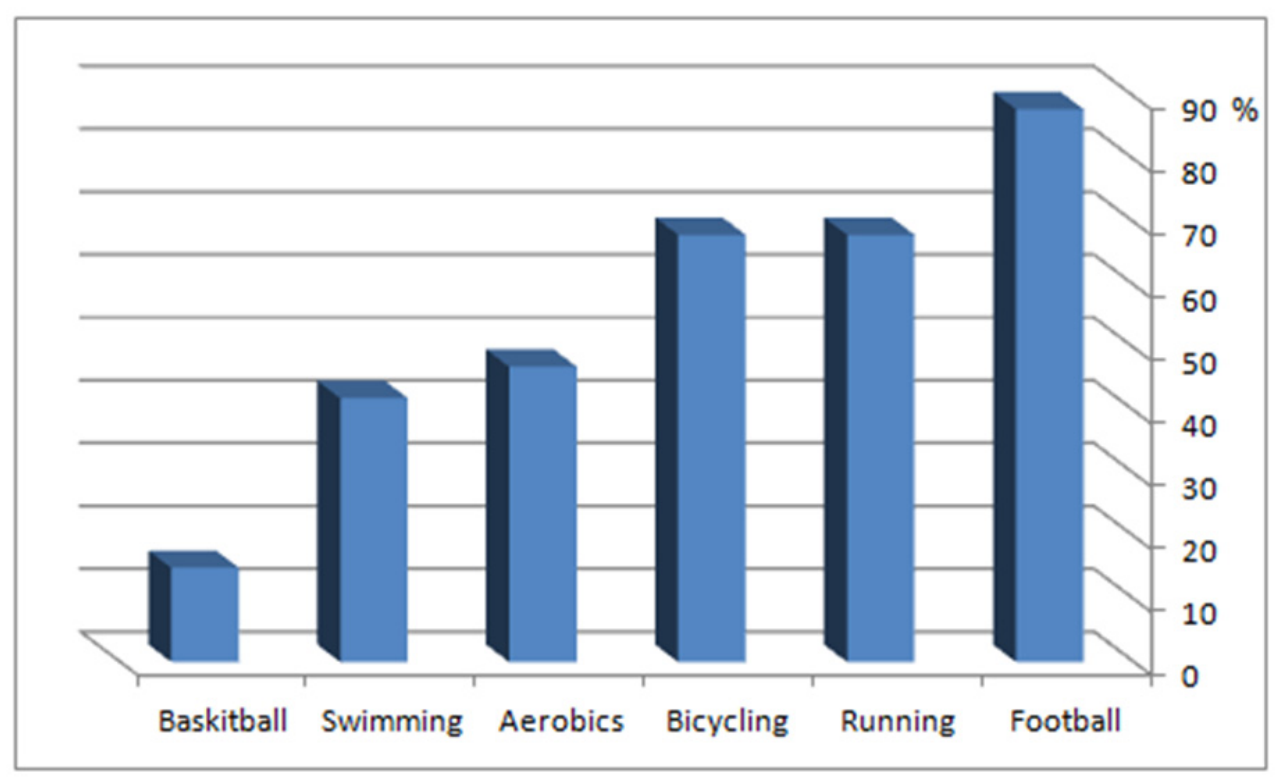

Figure 2. Outdoor sports practiced/week

There was a highly significant association between BMI and the time spent in watching TV, meaning that the prevalence of overweight / obesity was higher among children how spent more time in watching TV. The data showed also an increase in the prevalence of overweight/ obesity as the time of playing videogames increased. However, it was not statistically significant (Table 10). 
Table 10. Prevalence of overweight/obesity according to the time spent in watching TV and in playing videogames

\begin{tabular}{lllll}
\hline \multirow{2}{*}{ Sedentary life habits } & \multicolumn{3}{l}{ BMI Categories } & \\
\cline { 3 - 5 } & & Underweight & Normal weight & Increased weight \\
\hline Time spent in watching TV/day & $<3$ hours & $17(10.6 \%)$ & $109(68.1 \%)$ & $34(21.3 \%)$ \\
& $\geq 3$ hours & $7(8.8 \%)$ & $36(45 \%)$ & $37(46.3 \%)$ \\
\hline P-value $<0.0001$ & & & $114(63.3 \%)$ & $47(26.1 \%)$ \\
\hline $\begin{array}{l}\text { Time spent in playing } \\
\text { videogames/day }\end{array}$ & $<3$ hours & $19(10.6 \%)$ & $31(51.7 \%)$ & $24(40 \%)$ \\
\hline P-value $=0.1$ & $\geq 3$ hours & $5(8.3 \%)$ & &
\end{tabular}

P-value $=0.1$

Other factors were assessed regardless the prevalence of overweight/obesity. Factors were included (Table 11).

Table 11. Other factors

\begin{tabular}{ll}
\hline Factors & Percentage \\
\hline \begin{tabular}{l} 
Child's perception about obesity \& its $\begin{array}{l}\text { About obesity } \\
\text { future consequences }\end{array}$ \\
\cline { 2 - 2 }
\end{tabular} & Future DM and/or Hypertension \\
\hline Child's perception that fast food is a risk factor of obesity & $85 \%$ \\
Child's awareness that physical activity is a protective of obesity & $90.4 \%$ \\
parent's awareness about child's obesity & $96.7 \%$ \\
Specifying time for meal & $81.7 \%$ \\
Gathering of family during eating & $77.9 \%$ \\
Family attended lectures or courses regarding childhood obesity & $94.6 \%$ \\
\hline
\end{tabular}

In order to find the independent association between the selected risk factors and overweight/obesity, logistic regression analysis was carried out. The dependent variables was non-obese (normal and underweight) and obese (overweight, obese, and extremely obese). Table 12 shows the association of overweight/obesity with independent variables according to their significances, odds ratios, and confidence intervals. 
Table 12. Logistic regression analysis

\begin{tabular}{|c|c|c|c|c|}
\hline \multirow{2}{*}{ Variables } & \multirow{2}{*}{ P-value } & \multirow{2}{*}{ Odds ratio } & \multicolumn{2}{|c|}{ 95\% CI for odds ratio } \\
\hline & & & Lower & Upper \\
\hline \multicolumn{5}{|l|}{ A. Independent variables with significant association } \\
\hline Fathers' obesity & .021 & .078 & .009 & .681 \\
\hline Mothers' obesity & .001 & .038 & .006 & .240 \\
\hline Mothers' employment & .001 & .033 & .005 & .242 \\
\hline Early childhood obesity & .002 & .006 & .000 & .153 \\
\hline Number of snacks eaten/day & .003 & .163 & .050 & .533 \\
\hline Number of fast food eaten/week & .005 & 1.942 & 1.226 & 3.076 \\
\hline Eating during emotional stress & .008 & .045 & .005 & .443 \\
\hline Physical activity in leisure times & .008 & 7.267 & 1.659 & 31.827 \\
\hline Family eating together & .036 & .019 & .000 & .775 \\
\hline Family specifies time for meals & .014 & .075 & .009 & .598 \\
\hline Physical activity during physical educational classes & .025 & 23.270 & 1.472 & 367.962 \\
\hline Frequency of football playing/week & .010 & .132 & .029 & .611 \\
\hline Time spent in watching TV & .018 & 4.878 & 1.308 & 18.198 \\
\hline \multicolumn{5}{|l|}{ B. Variables with no significant association } \\
\hline Age of the child & .750 & .874 & .383 & 1.996 \\
\hline Place of residency & .596 & 1.420 & .388 & 5.206 \\
\hline Living with parents & .854 & 1.546 & .015 & 160.577 \\
\hline Father's age & .105 & .839 & .680 & 1.037 \\
\hline Mother's age & .082 & 1.223 & .975 & 1.534 \\
\hline Father's employment & .874 & .881 & .182 & 4.252 \\
\hline Monthly income of family & .357 & 1.318 & .732 & 2.373 \\
\hline Number of meals / day & .650 & 1.323 & .395 & 4.436 \\
\hline Healthy food items in a meal & .172 & 2.845 & .635 & 12.746 \\
\hline Activity in physical education classes & .103 & .544 & .262 & 1.132 \\
\hline Outdoor physical activity & .059 & .419 & .170 & 1.033 \\
\hline Eating while watching TV & .278 & 2.672 & .452 & 15.787 \\
\hline Family awareness of child's eating habits & .707 & .753 & .172 & 3.293 \\
\hline Food accessibility for child & .500 & 1.740 & .347 & 8.713 \\
\hline Family awareness of child's obesity & .316 & .396 & .065 & 2.423 \\
\hline Family got advice regarding childhood obesity & .998 & .998 & .250 & 3.981 \\
\hline Father's education & .609 & .646 & .121 & 3.446 \\
\hline Mother's education & .186 & .342 & .070 & 1.677 \\
\hline Number of carbonated drinks / day & .166 & 2.694 & .662 & 10.958 \\
\hline Time spent in videogames/day & .640 & 1.408 & .335 & 5.910 \\
\hline
\end{tabular}




\section{Discussion}

Obesity is a major public health problem resulting in serious social, physical and psychological damages (Koch, Sepa, \& Ludvigsson, 2008). The prevalence of obesity and overweight among adults and children is escalating in developed and developing countries including our region. Despite that, there are under-diagnosis and underreporting of the disease (Wijnhoven et al., 2008). In Al-Ahsa region, previous studies suggested that the prevalence of childhood overweight and obesity has markedly increased during the last few years (Amin, Al-Sultan, \& Ali, 2008). This was confirmed by the results of this study which found that the overall prevalence of overweight and obesity among primary and intermediate school children was $29.6 \%$ (10.8\% overweight, $3.8 \%$ obese, and $15 \%$ extremely obese). On the other hand, the prevalence of underweight was slightly lower than that of overweight/obesity, but it was still relatively high at 10\% (Al-Nakeeb et al., 2012).

The higher prevalence of overweight/obesity compared to that of previous studies and compared to children with underweight in this study, may suggest that Al-Ahsa is in a transitional state of increasing childhood overweight and obesity due to urbanization and to the changes in the lifestyle in the recent years. Although the prevalence of overweight and obesity among the school children in Al-Ahsa was relatively high, it is still lower than that reported in several neighboring regions in Saudi Arabia or other countries. For example, in Al-Khobar, Eastern province of Saudi Arabia, a study conducted in 2010 among children aged 2-18 years, showed that the prevalence of overweight/obesity was $42.3 \%$ (19.0\% were overweight and 23.3\% were obese) (Amin, Al-Sultan, \& Ali, 2008). While in Riyadh (2012), the prevalence of overweight/obesity among adolescents (14-18 years) was 38.3\% (Al-Nakeeb et al., 2012) Furthermore, a survey conducted in Saudi Arabia in 2010, has reported that the overall prevalence of overweight/obesity among Saudi children and adolescents (5-18 years) was $34.4 \%$ (23.1\% overweight, 9.3\% obese and 2\% severely obese) (El Mouzan et al., 2010). In Kuwait, a study published in 2009, revealed that the prevalence of overweight and obesity among school children was $45.3 \%(30.7 \%$ were overweight and $14.6 \%$ were obese) (El-Bayoumy, Shady, \& Lotfy, 2009). Another study conducted in Abu Dhabi, United Arab Emirates, illustrated that the prevalence of overweight/obesity was 33.6\% (14.7\% overweight and 18.9\% obese) (Al Junaibi, Abdulle, Sabri, Hag-Ali, \& Nagelkerke, 2012). On the other hand, the prevalence of overweight and obesity in the present study was similar to or higher than that reported for some neighboring regions in Saudi Arabia and Arab countries. In Abha City (South western of Saudi Arabia) in 2008, the prevalence of overweight and obesity estimated to be 16\% (Amin, Al-Sultan, \& Ali, 2008). While in Qatar (2007), the overall prevalence of overweight and obesity was 9.5\% (6\% were overweight and 3.5\% were obese) (Qotba \& Al-Isa, 2007). The prevalence of overweight and obesity in this study was markedly lower than that reported for American children, where the overall prevalence of overweight and obesity was $48.0 \%$ (16.5\% were bese, and $31.5 \%$ were overweight) (Ogden, Carroll, Curtin, Lamb, \& Flegal, 2010).

The differences in the results of those studies can be explained by the effect of genetic, environmental and lifestyle factors. In addition, part of the differences may be due to the variations in the age groups included, study methods and definitions of obesity and underweight across the various studies (Richardson et al., 2013).

It was suggested that the prevalence of overweight and obesity increased with age. This may give the impression that obesity is a progressing phenomenon that once present, tends to increase with time (Magarey, Daniels, Boulton, \& Cockington, 2008). The present study demonstrated that the prevalence of overweight and obesity increased with age. The prevalence of overweight and obesity increased from $16.9 \%$ at age $\leq 9$ years up to $52.1 \%$ at the age of 12 years and above. These results were consistent with those reported in another Saudi study and in several other studies in both the developed and in the neighboring countries (Al-Isa, Campbell, \& Desapriya, 2010; Mozaffari \& Nabaei, 2007). This finding might be attributed to less physical activity and more access to unhealthy foods among older compared to younger children. Older children are more likely to sit longer on TV games and reach fast food restaurants frequently and independent of their parents (Mayo clinic staff. Childhood obesity; 2010). However, the results from other countries such as Costa Rica (Núñez-Rivas, Monge-Rojas, León, \& Roselló, 2003) showed that the highest prevalence was in younger age group (7-9 years).

The present study found also that the obesity in early childhood was positively associated with the current high BMI status. This finding was supported by a British study which emphasized that most of the children who were obese at infancy till 34 months of age, were suffering from obesity at age of 7 years (odds ratio 15.00 , CI 5.32 to 42.30) (Reilly et al., 2005; Hughes et al., 2011).

Several studies illustrated that the prevalence of overweight and obesity was higher among children living in urban areas (Donatiello et al., 2012; Moraeus, Lissner, Yngve, Poortvliet, Al-Ansari, \& Sjöberg, 2011). In the present study, the prevalence of overweight/obesity was also higher in urban than in rural areas (56.3\% versus $43.7 \%)$. This is mostly due to the modern pattern of life and the obvious change in lifestyle among residents in urban 
compared to rural areas. Socioeconomic status (SES) has been described as inversely related to obesity in many studies (Coronado Vázquez et al., 2012; Wang \& Beydoun, 2007). Several studies have found that lower educational level of parents and non-working parents were associated with greater risk of overweight and obesity (Bertoncello et al., 2008; Bertoncello, Cazzaro, Ferraresso, Mazzer, \& Moretti, 2007). Furthermore, family income was inversely proportional to child's BMI in developed countries and directly proportional in developing countries (Bertoncello, Cazzaro, Ferraresso, Mazzer, \& Moretti, 2008).

The present study showed that there was no significant association between the prevalence of overweight / obesity and the parental educational levels. This was similar to what was found in a study which included 1458 schools in Wroclaw, Poland indicated that no significant relation between child's BMI and parental education (Kopelman, 2007).

Data in this study showed that childhood obesity was not affected by the father's work status. However, children of working mothers were having higher prevalence of overweight and obesity. The explanation of this might be the excessive consumption of pre-packed food, taking food away from home, and/or substituted main meals by fast food, thus leading to intake of unhealthy food. This result was consistent with the findings from a study conducted in Riyadh where the children of working mothers were most likely to be obese compared to those whose mothers were housewives (Al-Harthy, 2014).

It was shown from the literature that the presence of obesity in father and/or mother was associated with overweight or obesity in the children. Furthermore, obesity was more prevalent for those children when both parents were overweight compared with those with only one or neither parent was overweight (Mo-suwan, Tongkumchum, \& Puetpaiboon, 2000). This could be due to sharing genes and unhealthy dietary habits of obese subjects and their obese parents. The present study showed a higher prevalence of overweight and obesity among the children whose one or both parents were obese compared to those whose parents were not. The data showed also that the overweight / obesity in the included children was more significantly associated with maternal than paternal obesity. These findings were supported by many studies. For instance, a Chinese study conducted in school children and adolescents reported that, when both parents were overweight, this would increase the risk of a child being overweight or obese (Guo et al., 2013). In Riyadh's study, the subjects whose both parents were obese had significantly higher BMI compared to those whose parents were not obese. Another study conducted in Australia, included 329 children aged 6-13 years and their mothers, reported that, having an overweight mother increases the likelihood of a child being overweight or obese (Gibson et al., 2010). Furthermore, a study carried out in India in 2010, proved that the maternal obesity will affect the BMI of sons more than daughters, and vice versa (Kumar, Raju, \& Gowda, 2010).

Regarding the family income, the present study showed an increase in the prevalence of overweight and obesity with the increase in family income. This is most probably due to consumption of high caloric foods. This result was in agreement with the result of two studies conducted in Jordan and German which found that the total monthly family income was significantly associated with increased prevalence of overweight and obesity (Khader et al., 2009; Will, Zeeb, \& Baune, 2005). However, other two studies conducted in United States and in Riyadh revealed that the prevalence of childhood obesity was inversely associated with the family per capita income (Boyce, 2007).

In the present study, there was no significant association between the prevalence of overweight/obesity and the number of meals eaten per day. This result is consistent with what was found in two studies conducted in Riyadh and Al-Ahsa regions, in Saudi Arabia (Amin, Al-Sultan, \& Ali, 2008; Gibson et al., 2007). However, a Palestinian study carried out in 2009, has reported a significant association between additional meals and high BMI reading (Isbaih, 2009). With respect to the frequency of eating snacks, the present study showed a significant positive association between the prevalence of overweight and obesity and the number of snacks eaten per day. The explanation could be that the currently available snacks have a higher energy density which may contribute to a positive energy balance. A similar result was reported from a study published in Journal of pediatric gastroenterology and nutrition in 2008 (Maffeis et al., 2007).In contrast, a study conducted in Riyadh, showed that subjects who used to take 1-2 snacks daily had significantly higher level of BMI compared to those used to take three snacks daily. Moreover, an American survey concluded that, snakers, compared with nonsnackers, were less likely to be overweight or obese and less likely to have abdominal obesity (Keast, Nicklas, \& O’Neil, 2010). This fact could be because these children who regularly eating snacks were decreasing the amount of food consumed during the main meals.

Likewise, the present study found that the prevalence of overweight and obesity was significantly and progressively increasing with the frequency of fast foods that consumed in a week. This finding is consistent with 
several national and international studies. For instance, studies carried out in Saudi Arabia and Kuwait, revealed higher prevalence of obesity among children who were consuming fast food more frequently. Furthermore, a recent study conducted in Arkansas, United States (Alviola et al., 2013) indicated that the fast food is a main contributor in childhood obesity. Another British study reported that the consumption of fast food was associated with a higher $\mathrm{BMI}$ score $(\beta=0.08,95 \% \mathrm{CI}=0.03-0.14)$; higher body fat percentage $(\beta=2.06,95 \% \mathrm{CI}=1.33-2.79)$; and increased odds of being obese ( $\mathrm{OR}=1.23,95 \% \mathrm{CI}=1.02-1.49)$ (Fraser, Clarke, Cade, \& Edwards, 2012). The explanation might be the cheap prices and palatable taste of such fast foods, make them more desirable for children and adolescents.

In this study, the frequency of carbonated drinks consumption was also assessed. Despite that the prevalence of overweight and obesity was progressively increasing with high consumption of these drinks, the association was not statistically significant. In literature, studies conducted in United Kingdom, Mexico, and in Riyadh-Saudi Arabia, have demonstrated that the high consumption of sweetened beverages is a risk factor of obesity (James, Thomas, Cavan, \& Kerr, 2004; Ruvalcaba et al., 2009).

The present study showed that there was no statistically significant association was found between the prevalence of overweight/obesity and eating while watching TV. This was in contrast to the findings from a recent study that included eight European countries which found that the odds of being overweight was lower for children who reported to never watch TV at lunch and dinner compared to those who did (Vik et al., 2013). On the other hand, the prevalence of overweight and obesity in this study showed a significant independent association with eating during emotional stresses. This result was supported by a study which reported that the chronic life stress seems to be associated with a greater preference of high energy foods, which may be causally linked to weight gain (Torres \& Nowson, 2007).

It is well documented that the physical activity is inversely related to overweight and obesity in children and all age groups (Jafar et al., 2008).Physical inactivity during the early years of life is currently indicated as a major contributor to the increasing levels of obesity, and other serious medical conditions, seen in children and adolescents (Speiser et al., 2005). The present study showed a significant association between lower BMI scores among the included subjects and practicing physical activities during leisure times. This was consistent with a German study, which found that the prevalence of obesity was higher among inactive children during the leisure times (Graf et al., 2004).

This study showed a significant increase in the prevalence of overweight and obesity among those children who were not playing football or playing less than four times a week. However, other sports were not significantly associated. This could be because the football is the most popular sport all over the world and among children of all social classes.

The present study showed also a significant association between the prevalence of overweight/obesity and the extent of physical activity during physical education classes. A similar finding reported by an American study, which stated that the physical education classes reduced the BMI of overweight girls, however, it was not significant for overweight boys (116). Another Australian study revealed that the physical educational programs at schools were effective in reducing BMI, especially when they handled by professional trainers (Datar \& Sturm, 2004).

Several studies related watching TV and playing video games with childhood obesity (Maffeis et al., 2008; James, Thomas, Cavan, \& Kerr, 2004; Torres \& Nowson, 2008). The present study supported this finding, which showed that watching TV more than three hours in a day was significantly associated with the high BMI. The possible explanations could be that the screen time may displace more active pursuits, advertising of junk food and fast food increases children's requests for those particular foods and products, snacking increases while watching TV or movies, and late-night screen time may interfere with getting adequate amounts of sleep, which is a known risk factor for obesity (Telford et al., 2012). This finding was in agreement with a recent study conducted in Saudi Arabia, which revealed that the prevalence of obesity among the school children was increased with increase in hours of watching TV (El Mouzan et al., 2010). Another Canadian study reported that, the odds of being overweight increased by $8 \%$ for every 30 minutes of additional time spent in watching television between school and dinner on a typical school day (Strasburger, 2011).

However, the present study showed insignificant association between the prevalence of overweight / obesity and the time spent in playing videogames, nevertheless, several studies proved that the videogames could be a risk factor of obesity (Tudor-Locke, Craig, Cameron, \& Griffiths, 2011). 


\section{Conclusion}

This study found a relatively high prevalence of overweight and obesity among public Primary and intermediate school boys in Al-Ahsa region. The prevalence was $29.6 \%$ (10.8\% overweight, 3.8\% obese, and $15 \%$ extremely obese), however it is still lower than that reported for several neighboring places. The prevalence consistently increased with the increase in child's age. Moreover, significant association was found between overweight/obesity and presence of obesity in early childhood. Children whose parents were obese showed a higher prevalence of overweight/obesity than those whose parents were not. The prevalence of overweight/obesity among the included children was directly proportional to the family income and mother's employment. There was no significant association found between the prevalence of overweight /obesity and number of meals eaten per day. However, the frequency of snacks and fast food was significantly associated. While eating during emotional stress, gathering of family during eating, and specifying regular times for meals were independently associated with the prevalence of obesity. Physical activity during physical education classes and in leisure times as well as frequency of playing football per week, all were inversely associated with overweight/obesity. Moreover, spending of 3 hours or more in watching TV per day found to be significantly associated with high BMI levels.

\section{Competing Interests Statement}

The authors declare that there are no competing or potential conflicts of interest.

\section{References}

Al Dossary, S. S., Sarkis, P. E., Hassan, A., Ezz El Regal, M., \& Fouda, A. E. (2010). Obesity in Saudi children: a dangerous reality. Retrieved from http://www.ncbi.nlm.nih.gov/pubmed/21218729

Al Junaibi, A., Abdulle, A., Sabri, S., Hag-Ali, M., \& Nagelkerke, N. (2013). The prevalence and potential determinants of obesity among school children and adolescents in Abu Dhabi, United Arab Emirates. International Journal of Obesity, 37(1).

Al-Ghamdi, S. H. (2013). The association between watching television and obesity in children of school-age in Saudi Arabia. Journal of family \& community medicine, 20(2), 83.

Al-Harthy, M. S. A. S. (2008). Risk Factor Associated with Obesity in children Age 6-12 year in Nutritional Clinic of Security Forces Hospital in Riyadh City. (MSc thesis, King Saud University, 2008). Retreived 12 April, 2014, from http://repository.ksu.edu.sa/jspui/handle/123456789/8854

Al-Hazzaa, H. M. (2007). Prevalence and trends in obesity among school boys in Central Saudi Arabia between 1988 and 2005. Saudi medical journal, 28(10), 1569.

Al-Isa, A. N., Campbell, J., \& Desapriya, E. (2010). Factors associated with overweight and obesity among Kuwaiti elementary male school children aged 6-10 years. International journal of pediatrics, 2010.

Al-Nakeeb, Y., Lyons, M., Collins, P., Al-Nuaim, A., Al-Hazzaa, H., Duncan, M. J., \& Nevill, A. (2012). Obesity, physical activity and sedentary behavior amongst British and Saudi youth: A cross-cultural study. International journal of environmental research and public health, 9(4), 1490-1506. https://doi.org/10.3390/ijerph9041490

Al-Nuaim, A. A., Al-Nakeeb, Y., Lyons, M., Al-Hazzaa, H. M., Nevill, A., Collins, P., \& Duncan, M. J. (2012). The prevalence of physical activity and sedentary behaviours relative to obesity among adolescents from Al-Ahsa, Saudi Arabia: rural versus urban variations. Journal of nutrition and metabolism, 2012. https://doi.org/10.1016/j.jpeds.2008.06.016

Al-Rukban, M. O. (2003). Obesity among Saudi male adolescents in Riyadh, Saudi Arabia. Saudi medical journal, 24(1), 27-33.

Alviola, P. A., Nayga, R. M., Thomsen, M. R., Danforth, D., \& Smartt, J. (2014). The effect of fast-food restaurants on childhood obesity: a school level analysis. Economics \& Human Biology, 12, 110-119.

Amin, T. T., Al-Sultan, A. I., \& Ali, A. (2008). Overweight and obesity and their relation to dietary habits and socio-demographic characteristics among male primary school children in Al-Hassa, Kingdom of Saudi Arabia. European journal of nutrition, 47(6), 310. https://doi.org/10.1007/s00394-008-0727-6

Baker, J. L., Olsen, L. W., \& Sørensen, T. I. A. (2007). Childhood body-mass index and the risk of coronary heart disease in adulthood. $N$ Engl $J$ Med., 357(23), 2329-37. https://doi.org/10.1056/NEJMoa072515

Bell, L. M., Curran, J. A., Byrne, S., Roby, H., Suriano, K., Jones, T. W., \& Davis, E. A. (2011). High incidence of obesity co - morbidities in young children: A cross - sectional study. Journal of paediatrics and child health, 
47(12), 911-917. https://doi.org/10.1111/j.1440-1754.2011.02102.x

Bertoncello, C., Cazzaro, R., Ferraresso, A., Mazzer, R., \& Moretti, G. (2008). Prevalence of overweight and obesity among school-aged children in urban, rural and mountain areas of the Veneto Region, Italy. Public health nutrition, 11(9), 887-890. https://doi.org/10.1017/S1368980007001152

Bertoncello, C., Cazzaro, R., Ferraresso, A., Mazzer, R., \& Moretti, G. (2008). Prevalence of overweight and obesity among school-aged children in urban, rural and mountain areas of the Veneto Region, Italy. Public health nutrition, 11(9), 887-890. https://doi.org/10.1017/S1368980007001152

Boyce, T. (2007). The media and obesity. Obesity reviews, 8(s1), 201-205. https://doi.org/10.1111/j.1467-789X.2007.00342.x

Coronado, V. V., Odero, S. D., Canalejo, G. D., \& Cidoncha, P. J. (2011). Prevalence of overweight and obesity in schoolchildren in rural areas. Gaceta sanitaria, 26(5), 460-462.

Datar, A., \& Sturm, R. (2004). Physical education in elementary school and body mass index: evidence from the early childhood longitudinal study. American journal of public health, 94(9), 1501-1506. https://doi.org/10.2105/AJPH.94.9.1501

Donatiello, E., Russo, M. D., Formisano, A., Lauria, F., Nappo, A., Reineke, A., ... \& Siani, A. (2013). Physical activity, adiposity and urbanization level in children: results for the Italian cohort of the IDEFICS study. Public Health, 127(8), 761-765.

Eating, H., \& Activity, P. (2013). Durham E-Theses An intervention to promote Healthy Eating and Physical Activity in Lebanese School children: Health-E-PALS a pilot cluster randomised controlled trial. 2013;

El Mouzan, M. I., Foster, P. J., Al Herbish, A. S., Al Salloum, A. A., Al Omer, A. A., Qurachi, M. M., \& Kecojevic, T. (2010). Prevalence of overweight and obesity in Saudi children and adolescents. Annals of Saudi medicine, 30(3), $203 . \quad$ Retrieved from http://www.pubmedcentral.nih.gov/articlerender.fcgi?artid=2886870\&tool=pmcentrez\&rendertype=abstract

El-Bayoumy, I., Shady, I., \& Lotfy, H. (2009). Prevalence of obesity among adolescents (10 to 14 years) in Kuwait. Asia Pacific Journal of Public Health, 21(2), 153-159. https://doi.org/10.1177/1010539509331786

Fraser, L. K., Clarke, G. P., Cade, J. E., \& Edwards, K. L. (2012). Fast food and obesity: a spatial analysis in a large United Kingdom population of children aged 13-15. American journal of preventive medicine, 42(5), e77-e85. https://doi.org/10.1016/j.amepre.2012.02.007

Gibson, L. Y., Byrne, S. M., Davis, E. A., Blair, E., Jacoby, P., \& Zubrick, S. R. (2007). The role of family and maternal factors in childhood obesity. Medical Journal of Australia, 186(11), 591.

Graf, C., Koch, B., Dordel, S., Schindler-Marlow, S., Icks, A., Schüller, A., ... \& Predel, H. G. (2004). Physical activity, leisure habits and obesity in first-grade children. European Journal of Cardiovascular Prevention \& Rehabilitation, 11(4), 284-290. https://doi.org/10.1097/01.hjr.0000129740.30593.18

Gumbiner, B. (2001). Obesity. Philadelphia: American college of Physicians.

Guo, X., Zheng, L., Li, Y., Zhang, X., Yu, S., Yang, H., ... \& Sun, Y. (2013). Prevalence and risk factors of being overweight or obese among children and adolescents in northeast China. Pediatric research, 74(4), 443-449. https://doi.org/10.1038/pr.2013.116

Hughes, A. R., Sherriff, A., Lawlor, D. A., Ness, A. R., \& Reilly, J. J. (2011). Incidence of obesity during childhood and adolescence in a large contemporary cohort. Preventive medicine, 52(5), 300-304. https://doi.org/10.1016/j.ypmed.2011.02.014

Isbaih, M. A. E. N. (2009). Prevalence of Overweight and Obesity among School-Age Children in Nablus City (Doctoral dissertation, Faculty of Graduate Studies Prevalence of Overweight and Obesity among School-Age Children in Nablus City By Muntaha Abd Elateef Nemer Isbaih Supervisor Dr. Ansam Sawalha Co-Supervisor Dr. Samer Hamidi Submitted in Partial Fulfillment of the Requirements for the Degree of Master of Public Health, Faculty of Graduate Studies, An-Najah National University).

Jafar, T. H., Qadri, Z., Islam, M., Hatcher, J., Bhutta, Z. A., \& Chaturvedi, N. (2008). Rise in childhood obesity with persistently high rates of undernutrition among urban school-aged Indo-Asian children. Archives of disease in childhood, 93(5), 373-378. https://doi.org/10.1136/adc.2007.125641

James, J., Thomas, P., Cavan, D., \& Kerr, D. (2004). Preventing childhood obesity by reducing consumption of $\begin{array}{llllll}\text { carbonated drinks: cluster randomised controlled trial. } B m j, & 328(7450), & 1237 .\end{array}$ 
https://doi.org/10.1136/bmj.38077.458438.EE

Janssen, I. (2013). The Public Health Burden of Obesity in Canada. Canadian Journal of Diabetes, 90-96. https://doi.org/10.1016/j.jcjd.2013.02.059

Keast, D. R., Nicklas, T. A., \& O'neil, C. E. (2010). Snacking is associated with reduced risk of overweight and reduced abdominal obesity in adolescents: National Health and Nutrition Examination Survey (NHANES) 1999-2004. The American journal of clinical nutrition, 92(2), 428-435. https://doi.org/10.3945/ajcn.2009.28421

Khader, Y., Irshaidat, O., Khasawneh, M., Amarin, Z., Alomari, M., \& Batieha, A. (2009). Overweight and obesity among school children in Jordan: prevalence and associated factors. Maternal and child health journal, 13(3), 424. https://doi.org/10.1007/s10995-008-0362-0

Kliegman, R. M., Behrman, R. E., Jenson, H. B., \& Stanton, B. M. (2007). Nelson Textbook of Pediatrics E-Book (18th ed., p. 232-242). Elsevier Health Sciences.

Kopelman, P. (2007). Health risks associated with overweight and obesity. Obesity reviews, 8(s1), 13-17. https://doi.org/10.1111/j.1467-789X.2007.00311.x

Kumar, S., Raju, M., \& Gowda, N. (2010). Influence of parental obesity on school children. Indian journal of pediatrics, 77(3), 255-258. https://doi.org/10.1007/s12098-010-0015-3

Maffeis, C., Grezzani, A., Perrone, L., Del Giudice, E. M., Saggese, G., \& Tato, L. (2008). Could the savory taste of snacks be a further risk factor for overweight in children?. Journal of pediatric gastroenterology and nutrition, 46(4), 429-437. https://doi.org/10.1097/MPG.0b013e318163b850

Magarey, A., Daniels, L. A., Boulton, T., \& Cockington, R. A. (2003). Predicting obesity in early adulthood from childhood and parental obesity. International journal of obesity, 27(4), 505-513. https://doi.org/10.1038/sj.ijo.0802251

Magarey, A., Daniels, L. A., Boulton, T., \& Cockington, R. A. (2003). Predicting obesity in early adulthood from childhood and parental obesity. International journal of obesity, 27(4), 505-513. https://doi.org/10.1038/sj.ijo.0802251

Mahfouz, A. A., Abdelmoneim, I., Khan, M. Y., Daffalla, A. A., Diab, M. M., Al-Gelban, K. S., \& Moussa, H. (2007). Obesity and related behaviors among adolescent school boys in Abha City, Southwestern Saudi Arabia. Journal of tropical pediatrics, 54(2), 120-124. https://doi.org/10.1093/tropej/fmm089

Mayo clinic staff. Childhood obesity; 2010. Retrieved March 24, 2014, from http://www.mayoclinic.com /health/obesityinchildren.html

Mirmiran, P., Sherafat-Kazemzadeh, R., Jalali-Farahani, S., \& Azizi, F. (2010). Childhood obesity in the Middle East: a review/Revue sur l'obesite de l'enfant au Moyen-Orient. Eastern Mediterranean health journal, 16(9), 1009.

Moraeus, L., Lissner, L., Yngve, A., Poortvliet, E., Al-ansari, U., \& Sjöberg, A. (2011). Can lifestyle explain the urban-rural gradient in overweight and obesity observed in Swedish schoolchildren?. Obesity Reviews, 12, 95.

Mo-Suwan, L., Tongkumchum, P., \& Puetpaiboon, A. (2000). Determinants of overweight tracking from childhood to adolescence: a 5 y follow-up study of Hat Yai schoolchildren. International Journal of Obesity \& Related Metabolic Disorders, 24(12). https://doi.org/10.1038/sj.ijo.0801432

Mozaffari, H., \& Nabaei, B. (2007). Obesity and related risk factors. Indian journal of pediatrics, 74(3), 265-267. https://doi.org/10.1007/s12098-007-0041-y

Núñez-Rivas, H. P., Monge-Rojas, R., León, H., \& Roselló, M. (2003). Prevalence of overweight and obesity among Costa Rican elementary school children. Revista Panamericana de Salud Pública, 13(1), 24-32. https://doi.org/10.1590/S1020-49892003000100004

Ogden, C. L., Carroll, M. D., Curtin, L. R., Lamb, M. M., \& Flegal, K. M. (2010). Prevalence of high body mass index in US children and adolescents, 2007-2008. Jama, 303(3), 242-249. https://doi.org/10.1001/jama.2009.2012

Ogden, C. L., Carroll, M. D., Kit, B. K., \& Flegal, K. M. (2012). Prevalence of obesity and trends in body mass index among US children and adolescents, 1999-2010. Jama, 307(5), 483-490. https://doi.org/10.1001/jama.2012.40 
Qotba, H., \& Naser Al-Isa, A. (2007). Anthropometric measurements and dietary habits of schoolchildren in Qatar. International journal of food sciences and nutrition, 58(1), 1-5. https://doi.org/10.1080/09637480601041086

Rausch, J. C., Rothbaum Perito, E., \& Hametz, P. (2011). Obesity prevention, screening, and treatment: Practices of pediatric providers since the 2007 expert committee recommendations. Clinical Pediatrics, 50(5), 434-441.

Reilly, J. J. (2005). Descriptive epidemiology and health consequences of childhood obesity. Best Practice and Research Clinical Endocrinology and Metabolism, 19, 327-341. https://doi.org/10.1016/j.beem.2005.04.002

Reilly, J. J., Armstrong, J., Dorosty, A. R., Emmett, P. M., Ness, A., Rogers, I., ... \& Sherriff, A. (2005). Early life risk factors for obesity in childhood: cohort study. Bmj, 330(7504), 1357. https://doi.org/10.1136/bmj.38470.670903.E0

Richardson, A. S., North, K. E., Graff, M., Young, K. M., Mohlke, K. L., Lange, L. A., ... \& Gordon - Larsen, P. (2014). Moderate to vigorous physical activity interactions with genetic variants and body mass index in a large US ethnically diverse cohort. Pediatric obesity, 9(2).

Ruvalcaba, C. L. G., Vásquez-Garibay, E., Romero-Velarde, E., Troyo-Sanromán, R., Cabrera-Pivaral, C., \& Magaña, O. R. (2009). Sweetened beverages as a risk factor for adolescent obesity in Guadalajara, Mexico. BioMedHosp Infant Mex, 66, 522-528.

Smith, A. J., Skow, Á., Bodurtha, J., \& Kinra, S. (2013). Health information technology in screening and treatment of child obesity: a systematic review. Pediatrics, 131(3), e894-e902.

Spear, B. A., Barlow, S. E., Ervin, C., Ludwig, D. S., Saelens, B. E., Schetzina, K. E., \& Taveras, E. M. (2007). Recommendations for treatment of child and adolescent overweight and obesity. Pediatrics, 120 (Supplement 4), S254-S288.

Speiser, P. W., Rudolf, M. C. J., Anhalt, H., Camacho-Hubner, C., Chiarelli, F., Eliakim, A., et al. (2005). Consensus statement: Childhood obesity. Journal of Clinical Endocrinology \& Metabolism, 90(3), $1871-87$. https://doi.org/10.1210/jc.2004-1389

Strasburger, V. C. (2011). Children, adolescents, obesity, and the media. Pediatrics, 128(1), $201-208$. https://doi.org/10.1542/peds.2011-1066

Telford, R. D., Cunningham, R. B., Fitzgerald, R., Olive, L. S., Prosser, L., Jiang, X., \& Telford, R. M. (2012). Physical education, obesity, and academic achievement: a 2-year longitudinal investigation of Australian elementary school children. American journal of public health, 102(2), 368-374. https://doi.org/10.2105/AJPH.2011.300220

The NHS Information Centre. (2009). Health Survey for England-2008 Trend Tables. London: The NHS Information Centre, 2009.

Torres, S. J., \& Nowson, C. A. (2007). Relationship between stress, eating behavior, and obesity. Nutrition, 23(11), 887-894. https://doi.org/10.1016/j.nut.2007.08.008

Tudor-Locke, C., Craig, C. L., Cameron, C., \& Griffiths, J. M. (2011). Canadian children's and youth's pedometer-determined steps/day, parent-reported TV watching time, and overweight/obesity: the CANPLAY Surveillance Study. International Journal of Behavioral Nutrition and Physical Activity, 8(1), 66. https://doi.org/10.1186/1479-5868-8-66

U.S. Department of Health and Human Services. Centers for Disease Control and Prevention. Youth Risk Behavior Surveillance-United States, 2005. MMWR 2006; 55(5).

Vik, F. N., Bjørnarå, H. B., Øverby, N. C., Lien, N., Androutsos, O., Maes, L., ... \& Manios, Y. (2013). Associations between eating meals, watching TV while eating meals and weight status among children, ages 10-12 years in eight European countries: the ENERGY cross-sectional study. International Journal of Behavioral Nutrition and Physical Activity, 10(1), 58. https://doi.org/10.1186/1479-5868-10-58

Wang, Y., \& Beydoun, M. A. (2007). The obesity epidemic in the United States-gender, age, socioeconomic, racial/ethnic, and geographic characteristics: A systematic review and meta-regression analysis. Epidemiologic reviews, 29(1), 6-28. https://doi.org/10.1093/epirev/mxm007

Wang, Y., \& Beydoun, M. A. (2007). The obesity epidemic in the United States-gender, age, socioeconomic, racial/ethnic, and geographic characteristics: a systematic review and meta-regression analysis. Epidemiologic reviews, 29(1), 6-28. https://doi.org/10.1093/epirev/mxm007 
Wang, Y., \& Lobstein, T. I. M. (2006). Worldwide trends in childhood overweight and obesity. Pediatric Obesity, l(1), 11-25. https://doi.org/10.1080/17477160600586747

Wijnhoven, T. M. A., Raaij, J. M. A., Spinelli, A., Rito, A. I., Hovengen, R., Kunesova, M., ... \& O'Dwyer, U. (2013). WHO European Childhood Obesity Surveillance Initiative 2008: weight, height and body mass index in 6-9 - year - old children. Pediatric obesity, 8(2), 79-97.

Will, B., Zeeb, H., \& Baune, B. T. (2005). Overweight and obesity at school entry among migrant and German children: a cross-sectional study. BMC Public Health, 5(1), 45. https://doi.org/10.1186/1471-2458-5-45

World Health Organization [WHO]. (1997). Obesity: preventing and managing the global epidemic. Geneva, Switzerland: Report of a WHO consultation on Obesity; WHO/NUT/NCD/98.1.

World Health Organization [WHO]. (2004). Fight childhood obesity to help prevent diabetes, say WHO \& IDF. In Fight childhood obesity to help prevent diabetes, say WHO \& IDF. Retrieved March 5, 2010, from http://www.who.int/mediacentre/news/releases/2004/ pr81/en/print.html

World Health Organization [WHO]. (2010). Ten facts on obesity; 2010. Retrieved March 18, 2014, from http://www.who.int/features/factfiles/obesity/facts/en/index $9 . h t m l$

World Health Organization [WHO]. (2011). Global Strategy on Diet, Physical Activity and Health. WHO; 2011. Retrieved March, 2014, from http://www.who.int/entity/dietphysicalactivity/en/index.html

\section{Copyrights}

Copyright for this article is retained by the author(s), with first publication rights granted to the journal.

This is an open-access article distributed under the terms and conditions of the Creative Commons Attribution license (http://creativecommons.org/licenses/by/4.0/). 